\title{
Abstracts
}

\section{Søren Winter}

\section{The Development of Decision-Making Theory: An Introduction}

The article presents and discusses the development of decision-making and policy-making theories within the last half century. From a rational point of departure two tracks can be identified. One focuses on formal and deductive models, rational choice being the foremost example. The other track is more behaviouralistic attempting to offer a more realistic description of decisionmaking. Such theories encompass models of bounded rationality and psychologically inspired decision-making theory; conflict-/bargaining models including incrementalism and Cyert og March's coalition-/bargaining model; and the garbage can model. The behaviouralistic track departs more and more from the rational origin. Finally, the article tentatively discusses the relative relevance of some of the theories across various phases of the policy-making process, policy-areas, political systems, time, and changing economic situations

\section{Poul Erik Mouritzen}

\section{Is Incrementalism only for the Good Times?}

The article explores the importance of the policy context and socio-economic context for incremental budgeting. The analyses are based on budget figures from all 275 Danish municipalities covering a four year period, from 1982 to 1986.

Both contexts are found to affect the application of incremental budgeting practices. Incrementalism is found particularly on highly politized services and particularly in periods af relative resource abundance. when the fiscal capabilities of government are reduced (fiscal stress) incrementalism becomes less dominant because fiscal policy-making in this situation tends to reflect changes in the environment.

An alternative to incrementalism, termed the "stop-go « method, is found to be very pervasive. The stop-go method implies that selected programs are put under scutiny in one year while other programs are selected for next year and so on. As a consequence expenditures tend to develop in cycles so that years of expansion are followed by years of standstill or moderate growth.

\section{Erik Albak}

\section{The Political Agenda - A Garbage Can? AIDS as an illustrative Case}

The formulation of the so-called "garbage can " model meant the first complete break with the rationality assumption in classical decision theory. The garbage can model does not consider decisions to be goal directed connections of solutions to problems. Instead, decisions are links between four independent, exogenous streams - streams of choice opportunities, problems, solutions, and participants - whose loose coupling is primarily to be explained by their simultaneity. The model is assumed to be most relevant in periods during which new value and belief systems are generated, and before they are fully understood and ordered in a new hierarchy. Political agenda building is an example of such a situation. The article investigates, to which extent the garbage can model may be utilized in the analysis of a concrete example of agenda building: AIDS in Denmark. 


\section{Peter Nannestad}

\section{"Rational-Choice" Theory and the Study of Economic Policy - An Overview}

In recent years rational choice theory has grown in importance within European political science. The subject af rational choice theory can be defined as the study of non-market decision making, for example political decision making. The existing literature may be classified according to various criteria, including the level of abstraction (or distance to "real world " problems) and the centrality of normative elements.

If rational choice theory is considered an approach (rather than a theory proper), it may be reduced to a methodological claim (methodological individualism) and an axiom (rational, utility-maximizing actors). The precise implications of these two centerpieces are not always clear, however.

One central field of study within rational choice theory is the interaction between the economy and politics. The Frey-Schneider model is a simple model of its interaction. It consists of a rational electorate holding the government responsible for the state and development of the economy, and a rational government manipulating the economy in order to ensure its re-election.

The Frey-Schneider model may be used as a framework for studying intercountry variations in economic crisis development $1974-79$, for example with respect to unemployment. It leads to the hypothesis that the development of unemployment is related to the political cost of unemployment (in terms of popular support) to the government. Empirical evidence in support of this interpretion can be found when analyzing crises policies in Austria, Germany, Denmark, Sweden, and the UK for the relevant period. 